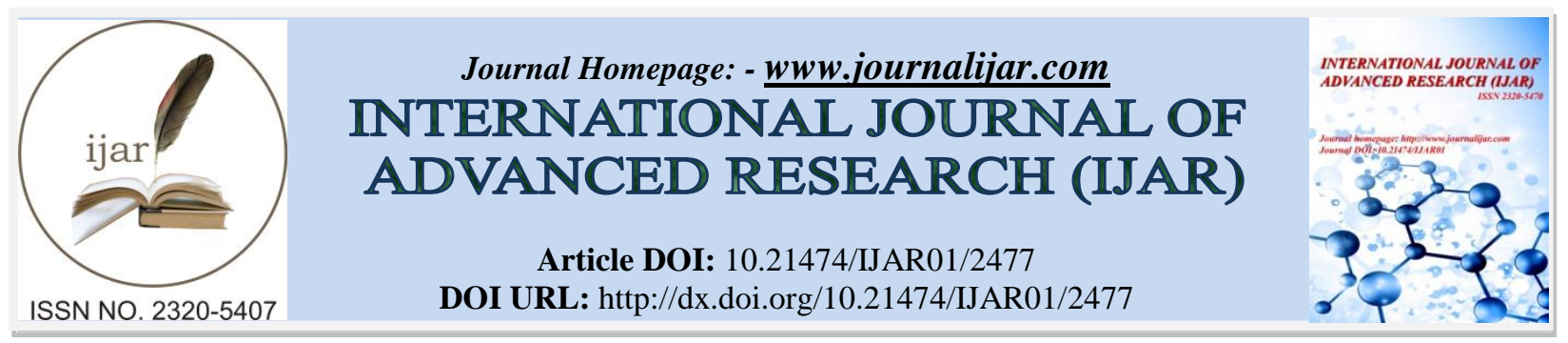

RESEARCH ARTICLE

\title{
CAREGIVING DURING ILLNESS: ADDITIONAL ECONOMIC BURDEN ON HOUSEHOLDS
}

\section{Dr. Savio P. Falleiro}

Vice Principal, Associate Professor, Head - Department of Economics, Rosary College of Commerce and Arts, Navelim, Goa (India) - 403707.

\section{Manuscript Info}

\section{Manuscript History}

Received: 23 October 2016

Final Accepted: 21 November 2016

Published: December 2016

Key words:-

Caregiver, Caregiving, HIV/AIDS,

Illness episodes

\section{Abstract}

No man is free from health related issues. While some episodes of sickness are trivial, others are major - those requiring elaborate treatment and care, with most necessitating the services of a caregiver. The present paper which draws on the findings of a field based study involving HIV/AIDS households highlights the role of a caregiver during illness episodes of a HIV infected member. Additionally, besides outlining the nature of economic loss entailed on account of caregiving, it brings out findings like how care receiving is a luxury for some, how women could be more adversely affected, and how minors and senior citizens are forced into caregiving. Based on its findings the paper concludes by listing a few suggestions related to caregiving and employment.

Copy Right, IJAR, 2016,. All rights reserved.

\section{Introduction:-}

Undergoing illness episodes are a part and parcel of the life of any individual. While on one hand illnesses/health concerns could be those that are periodic and trivial (which get alright on their own or by way of simple home remedy); on the other extreme it could refer to major ailments, like those related to heart and cancer. Needless to say, many ailments lie between the extremes - in terms of expenses, discomfort or time for recovery. While ailments / illness episodes cannot be wished away due to factors like genetic predisposition, viral air/water-borne infections, accidents and other causes not within ones control, they get accentuated due to sedentary lifestyles, poor diet, irresponsible behavior, ${ }^{1}$ lack of sanitation and hygienic conditions, pollution, malnutrition, etc.

India has the dubious distinction of having not only the largest population of poor, underfed and the unemployed in the world, but also of patients (Falleiro 2014b, 3-5). Poverty and its accompaniments like malnutrition, unhygienic conditions, lack of access to healthcare, sanitation and clean water have made the maintenance of healthcare all the more challenging. Over a decade ago, in the year 2005 alone, it was claimed that India lost \$8.7 billion in NI due to chronic diseases, with the figure estimated to be $\$ 54$ billion in 2015, i.e. about 1.27 percent of India's GDP (Bisserbe 2008, 6; Falleiro 2014b, 6). A study conducted by the London School of Economics found that India loses Rs. 69,000 crores a year to small infections; an amount more than twice the sum of Rs. 34,488 crores set aside by the country's health budget in 2012 (see Masand 2012: 1; Falleiro 2014b, 6 \& 17).

Notwithstanding, and in addition to fallouts like pain, decline in wellbeing and increase in stress and anxiety, illness episodes cast upon its victims financial liabilities. Financial liabilities could be broadly classified into: (i) those influencing the household incomes ${ }^{2}$ and those affecting the household expenditures ${ }^{3}$ (see Falleiro and Noronha 2011), and (ii) those that are direct (doctor's consultation fees, clinical tests and purchase of prescription medicines) 
and those which are indirect (fall in earnings due to absenteeism from work or reduction in hours of work due to weakness ${ }^{4}$ ). Two additional and incidental forms of financial liability caused by illnesses, both of an 'indirect' character, include the out-of-pocket expenses (OOP) and losses borne by caregivers.

OOP expenses refer to those indirectly associated with an ailment, for example, expenses incurred on transport (to go to the doctor/clinic for consultation), clinical tests (which are not provided free) and refreshments (on the day of the consultation/clinical tests). Needless to say OOP expenses are to be incurred even if the treatment, including consultation and medicines, are provided free by the government. India has one of the highest proportions of OOP spending on healthcare in the world, with an ILO report for 2010-11 indicating the figure to be about 76 percent compared to 13 percent in USA; the OOP expenses push almost 2-3 percent of Indians into the poverty trap each year (Mehdi 2008, 8; Falleiro 2014b, 5).

The present paper is an attempt to highlight select issues related to caregivers and caregiving in times of ill health. Among other things the paper tries to find if caregiving facility is available to those who need the same, who takes the responsibilities of being caregivers in a household setting, and what are the economic ramifications of caregiving on a caregiver / household. The paper draws on a field based study involving people living with HIV/AIDS (see Falleiro 2014a). This study was not conducted on caregivers per se, but on households having HIV/AIDS members (and on their care needs). While most studies are direct and independent analyses of caregivers/caregiving, this study is among the relatively fewer studies that focus on caregiving as an off-shoot or secondary outcome of an ailment. Being primarily a study of HIV/AIDS households (and not of caregivers), the sample respondents thus comprised of HIV infected members; caregivers who formed part of the study, got automatically selected on being members of the sample HIV/AIDS households.

\section{Caregivers and Caregiving:-}

A caregiver is a paid/unpaid person who helps another with impairment with his/her activities of daily living; any person with health impairment might use caregiving services to address their difficulties. ${ }^{5,6}$ According to Walker et al (1995), criterion for caregiving is dependence by one on another for any activity essential for daily living; caregiving is thus assistance provided to one who is dependent on the same (in D'Cruz 2004, 12; Falleiro 2014a). For the purpose of the present study, a caregiver would include a household member who takes care of an ill member (full time or part time).

In the context of caregiving to household members, such responsibilities can rest on the shoulders of any household member. Notwithstanding the same, it is women who are generally found performing caregiving roles (Medhini et al 2007b, 1090-1091; D'Cruz 2004, 17), including double-duty caregiving (Orzeck et al 2014, 3). While according to Stobert \& Cranswick (2004) women dedicate almost twice as much time to their caregiving tasks as men, according to Ward-Griffin et al (2005) they report more stress and burden, with Fast et al (2011) highlighting their experience of more employment related sacrifices due to caregiving responsibilities as compared to the males (in Orzeck et al 2014, 3-4).

Though caregiving has been documented to generally involve women, men are also found performing such roles (see DePaequale et al 2016; Kramer \& Thomson 2002). DePaequale et al (2016) while examining subjective stress appraisals and perceived schedule control among men employed in the long-term care industry who alongside performed unpaid family caregiving roles for children or older adults (double-duty caregivers), and both children and older adults (triple-duty caregivers), found that while workplace-only and double/triple-duty caregivers appraised primary stress similarly, differences emerged in terms of secondary strains like work-family conflict, emotional exhaustion and turnover intentions.

Notwithstanding the disproportionate burden shouldered by women as caregivers, children and senior citizens (those above 60 years of age) are not spared of such responsibilities. Children are the least acknowledged caregivers within the home, taking the adult role especially in nuclear families when a parent dies and there is no one to look after the others. Incidentally, in the context of caregiving to people living with HIV/AIDS in the household, the children caregivers could themselves be HIV-positive (D' Cruz 2004, 53; Falleiro 2014a, 40). Though in the context of HIV/AIDS households, not to exclude the others as well, with regard to those above 60 years as caregivers, it is not uncommon to have 'grandparents' performing such roles, often on account of incapacity, remunerative employment or death of 'parents' (D'Cruz 2004, 55; Dixit 2005, 142; Falleiro 2014a, 40; Pradhan et al 2006, 42; Pradhan \& Sundar 2006, 35; Singhal \& Rogers 2006, 23). 
Caregiving involves time cost as well as financial cost, the latter possibly including costs that are directly not linked to the care of the household member (Waechter 2015). The decision whether to remain in the workplace or commit to full-time caregiving is often influenced by the available support and services (Arksey \& Glendinning 2008, in Orzeck et al 2014). It is important to note that the decision to work for pay is rarely identified as a choice by caregiving employees; in this context women are differentially affected with there being a greater likelihood than men, to reduce their hours of work or quit their jobs if they are caregivers (Pavalko \& Henderson 2006; Killien 2004; in Orzeck et al 2014).

\section{Caregivers / caregiving in the context of HIV/AIDS households:-}

The field study was conducted on a sample of 200 households (117 male headed and 83 female headed) having at least one adult member who was HIV-positive (age group of 18-60 years). The HIV population being a hidden population, with no comprehensive and publicly accessible sampling frame being available, the study sample was selected with the help of a combination of non-probability methods including convenience, purposive and snowballing techniques as is universally done for such studies. While the mean age of the household head was 44.95 years $(\mathrm{SD}=12.82)$, it was 36.5 years $(\mathrm{SD}=8.73)$ in case of the adult HIV-positive member in the household. ${ }^{7}$ The average size of households in terms of members was 3.77 ( $\mathrm{SD}=1.86$ ). In case of majority of the households $(59$ percent), the HIV-positive status of the adult member was detected in the last 1-5 years, with the positive status in the case of 21.5 percent being detected less than a year, and that of 19.5 percent detected over 5 years earlier. Data collected (and as reflected herein) with regards to variables like income and expenditure are with reference to the standards and price levels prevailing in the year 2009.

Most of the sample elements belonged to the lower socio-economic background as evidenced with 95.5 percent belonging to households with income of up to Rs. 2 lakhs, half the sample having educational qualifications of up to Std. X, and with over one-third being illiterate (see Table 1). The fact that majority of the sample respondents were from the lower socio-economic households corroborates with the extensive literature available vis-à-vis the disproportionate impact of HIV/AIDS on poorer households, and how it is usually concentrated among those from the marginalized and poorer economic backgrounds (ADB 2004, 3; Bertozzi et al 2001; Dixit 2005, 142; Falleiro 2014a, 11-12; Kadiyala \& Barnett 2004, 1891; Mahal \& Rao 2005, 593); Medhini et al 2007b, 1088; Narain 2004, 29; Pellowski et al 2013; UNAIDS 2006, 84-85). While HIV can affect and has affected individuals irrespective of their socio-economic-cultural backgrounds, more cases have been recorded among the poorer sections because of reasons like: (i) lack of awareness/access to HIV prevention/protection; (ii) relatively greater prevalence of survival sex or prostitution in such households to make ends meet; and (iii) relatively more of such people availing the free HIV testing facilities provided by the government; the richer people generally go to private clinics (while the number of the former get recorded if tested positive, those of the latter go unreported/unrecorded).

Table 1:- Profile of households where the study of caregivers was conducted (all figures in \%)

\begin{tabular}{|l|c|}
\hline Level of educational qualification of the head of the household \\
\hline Illiterate & 37 \\
\hline Up to Std. X & 50 \\
\hline Up to graduation & 11 \\
\hline Post graduation/Others & 2 \\
\hline Total annual income of the household & 95.5 \\
\hline$\leq$ Rs 2 lakhs & 4.5 \\
\hline > Rs 2 lakhs & 23 \\
\hline Nature of earnings of the head of the household & 24.5 \\
\hline Salary & 10.5 \\
\hline Wage & 42 \\
\hline Self employed & \\
\hline Not applicable* &
\end{tabular}

Source: Author's field work

*Non-earning members on account of reasons like sickness and unemployment, or being housewives, retired etc.

HIV/AIDS has severe multi-faceted ramifications on individuals and households including those which are economic in nature. The economic impact itself can be of various hues including macro, sectoral and micro level impacts; impacts which are direct and those which are indirect in nature. One of the secondary fallouts of HIV/AIDS 
(having economic ramifications as well) is the gradual shift of attention and engagement of household members from remunerative activities to caregiving duties (Falleiro 2014a, 37). This is because HIV/AIDS often necessitates the assistance, services or time of another individual, i.e. the caregiver. Considering that most of the sample respondents belonged to households from the lower income brackets, having full time caregiving facility was a luxury that most could not afford considering that able members were required to work to contribute to household income. It needs to be mentioned here that while most households were poor ab initio, HIV/AIDS contributed to the poverty further. ${ }^{8}$ Rising expenses and falling incomes thus often made caregiving, whenever possible, only part-time in nature.

The study showed that majority of the households at about 55 percent required a caregiver to take care of the needs of the HIV-positive members. ${ }^{9}$ The average number of months for which caregiving was required was a little more than a year at 12.33 months $(\mathrm{SD}=15.1)$. While caregiving was required for as less as an entire month, the requirement went up to as high as 6 years. In the context of the overall sample, 21 percent households had no caregiving facility available though there was a need for the same. This figure goes higher to 38.5 percent if one considers only those households which needed caregiving but had no caregiver available even on a part-time basis.

The study showed that it was by and large female headed households that had no caregiving facility available though the same was required (while 51 percent of the female headed households needing services of a caregiver had no such benefit, the corresponding figure was 30 percent in case of male headed households). Chi-square analysis showed that there existed a significant association at the 0.5 level $(\mathrm{p}=0.024)$ between gender of the household head and whether caregiving was available, with the female headed households being found to be at a significant disadvantage. Notwithstanding that women are generally placed at a disadvantageous position in countries like India on various socio-economic-cultural indicators (all of which could also have had an influence on the female headed households not having caregiving facilities) one important factor responsible for the same as found by the present study was that in the case of female headed households 63 percent of the household heads themselves were HIVpositive. These often had not much scope of benefiting from caregiving because, besides not having a male head who generally is assumed to be an employed member (in many cases the male head had died, often on account of AIDS), the other household members were forced to go for remunerative employment to sustain the household (with the woman head often having to quit her own job due to the incapacities caused by the infection). In case of male headed households though, in spite of the fact that 74 percent of the heads were themselves HIV-positive, many could get the benefit of caregiving, at least on a part time basis, through their wives or other members (as the adverse economic impact on such households was relatively lesser than that faced by female headed households).

In households where there was the benefit of caregiving available, about 93 percent of the same was provided by a household member or close relative, with caregiving provided by a non-relative or external person being restricted to the remaining few. In the case of majority of the households at almost 54 percent, it was the spouse who took up the responsibility of caregiving, with children or parents providing caregiving in about 10.5 percent households each; siblings and other relatives acting as caregivers constituted a figure of about 18 percent. Care \& Support Homes and/or paid nurses/housemaids were among the non-household 'external' members/agencies providing caregiving in the remaining few cases.

The mean age of caregivers in the majority of the households where caregiving was done by household members themselves was a little over 35 years $(\mathrm{SD}=12.5)$. While the youngest caregiver was aged only 13 years, the oldest was 72 years. While majority of the caregivers at about 56.5 percent were within $31-50$ years of age, about 24 percent were within the 18-30 years age group with 5 percent being within 51-60 years. Almost 10 percent of the caregivers were minors ( $<18$ years of age), with close to 5 percent being senior citizens ( $>60$ years of age). As was mentioned earlier it is not uncommon, as the present study has also shown (at least in households with HIV/AIDS and/or from the poorer backgrounds) to have caregivers who are minors and senior citizens, i.e. the 'grandparents'

In the context of caregivers who were household members/relations, majority at about 61 percent were presently employed; of the remaining, leaving aside those studying, about 29 percent were into remunerative employment earlier, with two-thirds giving up their jobs on account of caregiving duties. In terms of occupation, about 30 percent of the caregivers were skilled/semi-skilled/non-agricultural labourers, followed by about 18.5 percent domestic servants, 14 percent who were into private / government service and about 11.5 percent each who were in construction and petty business; housewives and students constituted a figure of close to 5 percent each. ${ }^{10}$ It needs to be mentioned, especially with regard to female members who acted as caregivers, being domestic servants to 
supplement income was often a matter of choice on account of reasons like flexibility in work hours, proximity of the dwelling place to the work place, availability at least in some work places of a free meal/snack etc.

Almost 79 percent of the presently occupied caregivers reported loss of income due to caregiving duties. The fall in income was on account of reasons like not reporting for work, reduced hours of work per day/week, changing nature and/or place of occupation etc. The mean earnings lost due to caregiving was close to Rs. 2,800, with the maximum amount being Rs. 15,000 during the year. ${ }^{11}$ The income lost during the year (by those households where caregiving contributed to fall in earnings), taken as a percentage of the total annual household wage income, was about 5.55 percent. ${ }^{12}$ Incidentally, the mean amount of income lost by the caregivers who were employed earlier (currently not employed) was Rs. 1,220 per month $(\mathrm{SD}=538)$.

\section{Conclusion:-}

Despite the non-availability of full-time caregivers in most cases, with caregiving being done largely on a part-time basis and when absolutely needed only, there has been loss of income due to caregiving in HIV/AIDS households, in addition to the regular loss of income on account of death of earning HIV/AIDS members and loss of income of HIV-positive members (Falleiro 2014a). It needs to be mentioned that the adverse issues listed in this paper are those that primarily arise on account of caregiving for household members living with HIV/AIDS; caregiving services meant for non HIV-infected members can only make matters more adverse for these households.

Considering that 90 percent of care takes place at home, ${ }^{13,14}$ and that caregiving by and large involves women and those from the economically productive age-groups (not to exclude the senior citizens and the minor children as well), the increasing population being left to deal with the burden of care is a major livelihood concern (Medhini et al 2007b, 1090; Falleiro 2014a, 42). It is an area, however, that has not yet attracted enough formal attention especially in developing countries, including India. While caregiving facility is of utmost importance in the context of quick recovery and/or wellbeing of a sick person, compromising on remunerative employment on account of engagement in caregiving roles is something the majority can ill afford. Either way, households and its members lose out, especially considering the levels of poverty that a large section of the Indian population is living in. Minor children performing caregiving roles can contribute to mental ill health, poor psycho-social development (D'Cruz 2004, 54; Dixit 2005, 110; Medhini et al 2007a, 563-564) and insufficient education. Insufficient education could in turn make them less qualified for better jobs in the future, thereby contributing to the perpetuation of poverty and deprivation. Caregiving roles handled by women can subject them to time poverty, fatigue, emotional exhaustion, physical exertion and burn-out (Pradhan and Sundar 2006, 23). Things only get worse for women since besides caregiving duties being invariably thrust on them at the first instance (and not on men), they perform routine household chores plus remunerative work, which occasionally includes additional job(s) to supplement fast depleting household income (Falleiro 2014a, 42; Medhini et al 2007b, 1091; UNDP 2003, in Pradhan and Sundar 2006, 23). Women also undergo an empowerment cost when their time is taken from productive work to unpaid care of sick members; it is an opportunity cost which women have to pay since their ability to participate in skill building, income generating and leisure activities are drastically reduced (Pradhan and Sundar 2006, 23; Falleiro 2014a, 42).

Bearing in mind that care-receiving is a necessity that cannot be compromised and that remunerative work too cannot be given up (since income generation will adversely suffer, thereby reducing the quality of living especially in poorer households), there needs to be multi-pronged strategy to take care of households with members suffering from illnesses. And this is all the more in female headed households, particularly in cases of ailments which could be considered major, like for example HIV/AIDS, where women often bear a disproportionate burden even though the same is often concealed (Falleiro and Noronha 2013). Thus, while options to provide caregiving need to be worked on one hand, simultaneously, opportunities to sustain income flow during illness episodes of household members need to be maintained. At the same time the wellbeing of the caregiver him/herself cannot be compromised or ignored; a caregiver also needs proper nutrition, exercise, sleep and external support; a well cared for caregiver alone can provide quality caregiving to an ill member (see also CDC 2016; Waechter 2015).

Some options available to those in need of caregiving (but cannot afford for various reasons ranging from poverty to existence of single member households) are: (i) increasing the number of Care and Support Homes, as well as increasing the beds in existing ones to provide the much needed caregiving to those who cannot avail of the same in their own homes, (ii) providing flexibility in work hours and in the nature of duties performed at the workplace to employees who simultaneously do caregiving duties at home (if the nature of the job permits, allow the work 
allotted to be done from home), (iii) providing income earning opportunities to long-term/full time caregivers and/or to those incapable of taking up remunerative external employment, by way of providing easy loan facility and skill training (to start small home-centered businesses, sale outlets, or production units like tailoring), and (iv) proving monthly doles to households from below the poverty line who have members suffering from major/terminal illnesses.

\section{Notes:-}

1. For example, addiction to tobacco/smoking leading to throat/lung cancer, alcohol consumption leading to cirrhosis, casual/promiscuous sex leading to HIV, speeding/racing leading to self inflicted avoidable accidents etc.

2. Due to absenteeism from work due to illness and/or reduced productivity on account of weakness caused by the ailment.

3. Rise in expenses on account of doctor's consultation fees, clinical tests and purchase of prescription medicines.

4. Happens not only in the case of a daily wage earner but also in the case of a salaried person if the productive engagement is impinged for a long duration.

5. See: https://en.wikipedia.org/wiki/Caregiver.

6. A caregiver can also be defined as a person who provides direct care as for children, elderly people, or the chronically ill (See: www.merriam-webster.com/dictionary/caregiver).

7. Irrespective of the number of HIV-positive members in the household, only one was considered per household for the purpose of analysis.

8. HIV/AIDS is notorious for making relatively better-off households poor and poor households poorer (Falleiro 2014a, 50).

9. Caregiving facilities/services cited in this study/paper are primarily those meant for household members living with HIV/AIDS (and not for non-infected members who could occasionally also require such services as does happen in any household).

10. Other transport workers and retired/pensioners were the current 'occupations' of the remaining caregivers.

11. An earlier study conducted by ILO (2003) had reported the average loss being Rs. 2,200 (in Medhini et al 2007b, 1091).

12. Another study conducted in India had found that the income lost by caregivers due to absence from work was around 3.5 percent of the current income of the affected households (Pradhan et al 2006, xxii).

13. Retrieved from: http://www.helpage.org/researchandpolicy/HIVAIDS/factsandfigures.

14. In a rich country like United States, family caregivers were said to be giving over 75 percent of caregiving support; the estimated monetary value of family caregivers' unpaid contributions was estimated $\$ 450$ billion in the year 2009 (Science Care 2015).

\section{References:-}

1. ADB. 2004. Asia's economies and the challenge of AIDS. Asian Development Bank. Retrieved from: http://www.adb.org/Documents/Books/Asia-AIDS/

2. Arksey, H. and Glendinning C. 2008. Combining work and care: Carer's decision-making in the context of competing policy pressures. Social Policy and Administration, 42(1): 1-18.

3. Bertozzi, Stefano, Opuni M. and Juan-Pablo Gutiérrez. 2001. The economic impacts of HIV/AIDS. Retrieved from: http://ipsnews.net/aids/page_5.shtml

4. Bisserbie, Noemie. 2008. Corporate India wakes up to health risks. The Economic Times. February 12.

5. CDC. 2016. Disability and health: Family caregivers. Centers for Disease Control and Prevention. Retrieved from: http://www.cdc.gov/ncbddd/disabilityandhealth/family.html

6. D’Cruz, Premilla. 2004. Family care in HIV/AIDS: Exploring lived experience. New Delhi: Sage Publications.

7. DePasquale N, Zarit SH, Mogle J, Moen P, Hammer LB and Almeida DM. 2016. Double- and triple-duty caregiving men: An examination of subjective stress and perceived schedule control. J Appl Gerontol. pii: 0733464816641391. [Epub ahead of print] Retrieved from: https://www.ncbi.nlm.nih.gov/pubmed/27036637

8. Dixit, AP. (Ed). 2005. Global HIV/AIDS trends. Delhi: Vista International Publishing House.

9. Falleiro, Savio P. 2014a. Economic impact of HIV/AIDS on households. New Delhi: Sage Publications.

10. Falleiro, Savio P. 2014b. The state of health in India: The role of HIV/AIDS in the exacerbation of poverty. In Savio P. Falleiro and Afonso Botelho edited, Socio-economic inequities and the health sector: Issues and perspectives; 1: 1-22. Goa: CinnamonTeal Publishing. 
11. Falleiro, Savio P. and Noronha S. 2012. Economic impact of HIV/AIDS on women. Journal of Health Management, 14(4): 495-512.

12. Falleiro, Savio P. and Noronha S. 2011. Newer perspectives on the burden of HIV/AIDS on medical expenditures of individuals and households. Journal of Health Management, 13(3): 301-328.

13. Fast, J., Lero D., Duncan K., Dunlop C., Eales J., Keating N. and Yoshino, S. 2011. Fact sheet: Employment consequences of family/friend caregiving in Canada. Research on Aging, Policies and Practice. Edmonton, Alberta: University of Alberta.

14. ILO. 2003. Socio-economic impact of HIV/AIDS on people living with HIV/AIDS and their families; ILO India Project: Prevention of HIV/AIDS in the world of work: A tripartite response. New Delhi: ILO Publications.

15. Kadiyala, Suneetha and Barnett Tony. 2004. AIDS in India: Disaster in the making. Economic and Political Weekly, May 8: 1888-1892.

16. Killien, MG. 2004. Nurses' health: Work and family influences. The Nursing Clinics of North America, 39: 1935.

17. Kramer, BJ and Thomson Jr. EH. (Eds). 2002. Men as caregivers: Theory, research and service implications. New York: Springer.

18. Mahal, Ajay and Bhargavi Rao. 2005. HIV/AIDS epidemic in India: An economic perspective. Indian J Med Res, 121, April: 582-600.

19. Masand, P. 2012. Small infections cost Indians Rs 69,000 crore. The Times of India. October 16.

20. Medhini, Laya, Jain D. and Gonsalves C. (Eds) 2007a. HIV/AIDS and the law - Volume I. New Delhi: HRLN.

21. Medhini, Laya, Jain D. and Gonsalves C. (Eds). 2007b. HIV/AIDS and the law - Volume II. New Delhi: HRLN.

22. Mehdi, Ali. 2008. Is curative care the cure? The Economic Times. February 9.

23. Narain, Jai P. 2004. AIDS in Asia: The epidemic profile and lessons learnt so far. In Jai P. Narain edited, AIDS in Asia: The challenge ahead. 1: 19-41. New Delhi: WHO and SAGE Publications.

24. Orzeck, Pam, Brotman S, Drummond JD, Silverman M, Shiller I and Barylak L. 2014. Caregivers in the healthcare workplace (Findings from a 2008-2011 Action Research Project). Les cahiers du CREGÉS, Vol. 1. Retrieved from: http://www.creges.ca/wp-content/uploads/2015/06/Caregivers-in-the-HealthcareWorkplace_final.pdf

25. Pavalko, EK and Henderson KA. 2006. Combining care work and paid work. Research on Aging, 28(3), 359374.

26. Pellowski, JA., Kalichman SC., Matthews KA. and Adler N. 2013. A pandemic of the poor: Social disadvantage and the U.S. HIV epidemic. Am Psychol, 68(4): 197-209. Retrieved from: https://www.ncbi.nlm.nih.gov/pmc/articles/PMC3700367/

27. Pradhan, Basanta K. and Sundar Ramamani. 2006. Gender impact of HIV and AIDS in India. New Delhi: NCAER, NACO and UNDP.

28. Pradhan, Basanta K., Sundar R. and Singh S.K. 2006. Socio-economic impact of HIV and AIDS in India. New Delhi: NCAER, NACO and UNDP. Also available at: http://data.undp.org.in/hivreport/India_Report.pdf.

29. Rutman, D. 1996. Caregiving as women's work: Women's experiences of powerfulness and powerlessness as caregivers. Qualitative Health Research, 6(1): 90-111.

30. Science Care. 2015. Caregiving roles and responsibilities. 5 March. Retrieved from: http://www.sciencecare.com/caregiving-roles-and-responsibilities/

31. Singhal, Arvind and Rogers EM. 2006. Combating AIDS: Communication strategies in action. New Delhi: Sage Publications.

32. Stobert, S. and Cranswick K. 2004. Looking after seniors: Who does what for whom? Catalogue No. 11-008. C. S. Trends.

33. UNAIDS. 2006. Report on the global AIDS epidemic. Geneva: UNAIDS. Retrieved from: http://www.unaids.org/en/HIV_data/2006GlobalReport/default.asp

34. UNDP. 2003. Regional human development report: HIV/AIDS and development in South Asia.

35. Waechter, Judy. 2015. Caring for the caregiver: Understanding the importance of caregiver well-being. September 24. Retrieved from: https://crhcf.org/Blog/caring-for-the-caregiver-understanding-the-importanceof-caregiver-well-being/

36. Ward-Griffin, C., Brown J., Vandervoort A., McNair S. and Dashnay I. 2005. Double-duty caregiving: Women in the health professions. Canadian Journal on Aging / La Revue canadienne du vieillissement, 24(4): 379-394. 